\title{
SOBRE LOS NOMBRES DE LA FILOSOFÍA PRIMERA EN EL PROEMIO A LAS DISPUTATIONES METAPHYSICAE DE FRANCISCO SUÁREZ
}

\author{
On the Names of First Philosophy in the Proem \\ to Francisco Suárez's Disputationes Metaphysicae \\ José María Felipe Mendoza \\ Universidad Nacional de Cuyo, Argentina - CONICET
}

\section{Resumen}

El presente estudio realiza una detenida exégesis de los nombres de la ciencia metafísica de acuerdo con el proemio a las Disputationes metaphysicae de Francisco Suárez. La clave de su consideración estaría en la simultánea unidad de esta ciencia y los nombres que principalmente Aristóteles le asigna. Asimismo, al ser un texto que al presente ha sido escasamente atendido, se pretende destacar que la unidad epistémica de la metafísica está dada anticipadamente -antes de la consideración y determinación definitiva de su objeto adecuado, que es el ente en cuanto ente real- por la complementariedad de las diferentes perspectivas que cada nombre de dicha ciencia señala.

\section{Palabras clave}

Francisco Suárez; metafísica; ciencia especulativa

\begin{abstract}
This study provides a thorough exegesis of the names of metaphysics according to the proem of the Disputationes metaphysicae by Francis Suarez. The key to its consideration lies in the simultaneous unity between this science and the names assigned to it mainly by Aristotle. Due to the scant attention devoted to this work, this study emphasizes that the epistemic unity of metaphysics is given beforehand -prior to the final consideration and determination of its proper object, which is the entity insofar real entity- by the complementarity of the different perspectives each name of metaphysics denotes.
\end{abstract}

\section{Keywords}

Francis Suarez; metaphysics; speculative science

En el año 1597 aparecen editadas en Salamanca ${ }^{1}$ las Metaphysicarum disputationem in quibus et universa naturalis theologia ordinate traditur, et quaestiones omnes ad duodecim

1 Pueden consultarse para el contexto histórico de las universidades y el saber en general los siguientes textos: Cfr. Hale, J.R., La Europa del Renacimiento 1480-1520, Siglo XXI, Madrid, 2016, pp. 293-336. Cfr. Cfr. Parker, G., Europa en crisis 1598-1648, Madrid, Siglo XXI, 2017, pp. 354-373. Cfr. Rodríguez-San Pedro de Bezares, L.E., La Universidad Salmantina del Barroco, periodo 1598-1625, t. II: régimen docente y 
Aristotelis libros pertinentes accurate disputantur, Tomus prior et Tomus posterius -en adelante D.M.- del sacerdote jesuita Francisco Suárez. El título latino de esta obra se centra en la ciencia metafísica que trata también de toda la teología natural. De ahí que la amplitud de dicha ciencia incluye la totalidad de temas de la teología natural, de tal modo que esta última es una de sus partes fundamentales. Claramente ella no es una ciencia diferente de la metafísica, sino un ámbito del cual también se ocupa. Metafísica y teología natural son inseparables. Una ciencia de dos regiones donde la segunda especifica, mediante el tratamiento del Creador y lo creado, las consideraciones doctrinales y más generales de la primera. Esto es lo que se expresa en la primera parte del título, que, como se verá en la $D . M$. 1, guarda estrecha relación con el nombre de sabiduría. En cambio, la segunda parte del título destaca la base principal sobre la cual versa aquella ciencia. En efecto, las disputaciones tienen lugar y se llevan a cabo como tarea especulativa sobre los doce libros metafísicos de Aristóteles, dividiendo sus temas en dos ámbitos, cuestión que explicita nuevamente los nombres de metafísica y teología natural. Ya el título señala que no hay aquí una glosa a la Metafísica de Aristóteles, tal como se acostumbraba entre los autores medievales precedentes. Hay un tratamiento de la metafísica por tópicos, temas y tareas. Por esta razón, aquella división anunciada por Suárez no sigue el texto aristotélico capítulo por capítulo, sino que reorganiza la totalidad del tratado bajo la modalidad de una extensísima disputación según los temas que le son propios. El mismo Suárez lo explica en el 'motivo y plan de la obra' cuando dice: «en el primer tomo se examina el ente con sus propiedades y causas. En cambio en el segundo se consideran las razones inferiores del mismo objeto, comenzando desde la división en ente creado y Creador» ${ }^{2}-$ lo cual se refleja en el nombre de teología natural como ámbito incluido en aquel más amplio de la ciencia metafísica- .

Hasta aquí el título adelanta una variación respecto del tratamiento medieval de la metafísica. El título completo de las D.M. queda explicado cabalmente en el proemio a las D.M. 1 cuya introducción general a toda la obra pone de manifiesto el sentido de las relaciones entre metafísica y teología sobrenatural. De modo que la precisión del título completo gana claridad expositiva e intencional en la medida en que se atiende al movimiento especulativo que comienza en el motivo y plan de la obra, transita por el proemio a todas las D.M. y culmina con el prólogo a la primera disputación.

Una lectura atenta de los tres prólogos muestra la importancia de la consideración de la metafísica como una única ciencia que trata una diversidad de temas sin que ellos la fragmenten y provoquen su división en ciencias diferentes. El tercer prólogo puntualiza esta situación. En efecto, en su desarrollo sobre la unidad de la ciencia de la sabiduría aparecen, a modo de introducción, la mención de los nombres de la metafísica, evidenciando así las raíces medievales de una tradición onomástica donde los nombres o títulos de una ciencia emergen de la consideración del subiectum del cual tratan. Y así, la importancia de los nombres para designar las ciencias, muy propio de la filosofía escolástica medieval, subsiste y recorre especulativamente las páginas de las D.M. desde el comienzo, cuando el Dr. Eximio, en su

atmósfera intelectual, Salamanca, Universidad de Salamanca, 1986. Cfr. Gómez López, C., «La Renovatio Urbis: poder, ciudad y universidad en el s. XVI», Espacio, Tiempo y Reforma, Serie VII, Historia del Arte, 9 (1996), pp. 53-76. Cfr. Alejo Montes, F.J., «La Universidad de Salamanca en el s. XVI: la reforma educativa de D. Juan de Zuñiga (1594)» Studia histórica: Historia Moderna, 8 (1990), pp. 151-162.

2 Suárez, F., D.M. Ratio et discursus totius operis, ed. y trad. de S. Rábade Romeo, S. Caballero Sánchez y A. Puigcerver Zanón, Madrid, Biblioteca hispánica de filosofía, 1960, p. 18: «Deinde in priori tomo [...] In tomo autem altero inferiores eiusdem $[\ldots]$ ». 
brevísimo proemio a la cuestión I, sistematiza y coordina siete nombres para la ciencia de la filosofía primera ${ }^{3}$. De este modo Suárez, al introducir al lector en una consideración sistemática y autónoma de la mentada ciencia, considera apropiado, según aquella costumbre aludida, traer a colación todos sus nombres explicitando su sentido.

De acuerdo con ello el proemio destaca el único argumento que valida la colocación de los diferentes nombres. Se trata del hecho de que cada uno designa un aspecto diferente de un único saber, lo que evidencia, de forma clara y precisa, la amplitud de la ciencia metafísica, resguardando sin fisura su peculiar unidad epistémica. Los nombres de la filosofía primera no atentan contra la unidad de esta ciencia. La confirman por su complementariedad mediante la clarificación del subiectum del cual trata: el conceptus entis.

Según los considerandos previos el estudio que aquí presentamos se restringe únicamente a las explicaciones ofrecidas por Suárez sobre la unidad epistémica de la metafísica en relación con sus nombres según el proemio a la D.M. I.

\section{Breves consideraciones formales a modo de introducción}

No hay argumento que justifique suficientemente habernos detenido en el título, y hacerlo ahora en los prólogos, si no existiera una situación contemporánea que dé cuenta de ello. Y esta es la razón. Entre los estudiosos contemporáneos de las D.M. suarecianas no parece haber acuerdo definitivo acerca de si hay allí propiamente una ontología o más bien una metafísica clásica. Aquí aparece una primera respuesta formal. Suárez debe leerse desde las coordenadas de su propio tiempo buscando siempre que sea intérprete de sí mismo. Esta no es una cuestión baladí cuando el título de ontología para hacer referencia a su metafísica parece haber eclipsado el ámbito y el espectro de temas que el Dr. Eximio considera propios de esta ciencia. La tesis es clara. Acentuar el título de ontología para señalar la metafísica de Suárez lo coloca como filósofo moderno resignificando el modo y el objeto de la metafísica medieval precedente. A su vez ponderar la existencia de una metafísica al modo medieval tampoco parece hacer justicia sobre sus D.M. ${ }^{4}$.

Gilson había escrito a este respecto: «puede decirse que en el s. XVII la metafísica se convirtió en ontología antes de que Wolff hubiera divulgado el nombre y hecho resaltar todas las implicancias de la doctrina $»^{5}$. La aproximación de este estudioso francés a la metafísica de Suárez destaca el doble carácter de medieval y moderno que aquella obra tiene. El título de la obra, el tratamiento de la ciencia metafísica en disputaciones y las autoridades citadas dan cuenta de una intención especulativa netamente medieval, mientras que el efectivo modo en el que lleva a cabo la concreción de su plan de trabajo, esto es «habiéndose su autor separado

3 El siguiente estudio sigue en lo esencial la traducción de S. Rábade Romeo, aunque se aparta sólo en escasos términos que consideramos más apropiados en orden a una mejor intelección del latín. Así, por ejemplo, en vez de traducir subiectum por materia de una ciencia, hemos considerado más elocuente mantener la expresión latina en cuanto tal término refiere no solo la materia de la cual trata un saber sino también su base, fundamento y finalidad.

4 La ambigüedad entre metafísica y ontología puede observarse en: Barroso Fernández, Ó., «El objeto de la metafísica en Suárez y Zubiri» Revista de Filosofia Universidad de Costa Rica, XLIII, 109/110 (2005), pp. 225-2240, aquí p. 225: «Efectivamente la tradición aristotélico medieval ha entendido por metafísica tanto la teología natural - ciencia del ser supremo - como, en lenguaje moderno, la ontología - ciencia del ente en cuanto ente $-\gg$.

5 Gilson, E., El ser y la esencia, Buenos Aires, Desclée de Brouwer, 1951, p. 151. 
deliberadamente de toda sujeción al texto de la metafísica de Aristóteles» ${ }^{6}$ y dirigiéndose así «por los mismos objetos de la metafísica» ${ }^{7}$, señalaría su vertiente moderna. Las precauciones de Gilson de atribuirle el nombre de ontología a la metafísica de Suárez son también explicitadas por Fernández Burillo al afirmar: «He aquí una de las anécdotas más increíbles de la historia de la filosofía: que se le haga responsable [a Suárez] del primer tratado de Ontología, en una línea preracionalista que solo podía alumbrar a Descartes, Leibniz y Wolff $\rangle^{8}$. Por su parte, Forlivesi impugna los nombres de ontología y ontoteología como títulos legítimos para interpretar las D.M. en los siguientes términos:

Ció che maggiormente rileva è che le analisi compiute mostrano che è errato presentare las Disputationes del nostro autore nei termini di una refondation de la métaphysique como ontologie [J.-P. Cojou, Suarez et la refondation de la Métaphysique comme ontologie. Étude et traduction de l'index de la Métaphysique d'Aristote de F. Suarez, Institut supérieur de philosophie, Peeters, Paris, 1999.]. Mostrano che ció che è impuro non è semplicemente l'ontologia suareziana; è (prendendo il termine nel senso di indebita) l'applicazione ad essa delle stesse nozioni di ontología e ontoteologia9 .

Los tres estudiosos coinciden en negarle a Suárez un tratado de ontología moderna, favoreciendo, por contraste, un estudio del concepto de ente en cuanto ente real como lo propio de su metafísica. Hay en Suárez una metafísica y no una ontología. Contra esta interpretación aparece otra forma de leer las D.M. regida por el nombre de ontología, y cuyo origen estaría dado en la exégesis heideggeriana. A este respecto Poncela González afirma: «sostenemos que el concepto de la metafísica suareciana manejado por Heidegger está determinado por su comprensión de la Metafísica de Aristóteles. Y éste, que se resume en su conocida interpretación ontoteológica de la metafísica, se halla influenciada a su vez por el debate historiográfico sostenido en Alemania a principios del s. $\mathrm{XX} »^{10}$. Espósito, inspirado en esta línea hermenéutica, nos dice:

Esta ratio entis es literalmente absoluta en cuanto precede -como concepto objetivotanto al Creador como a la creatura (es decir, los entes determinados), permitiendo pensarlos a ambos. Aquí está la raíz de la interpretación suareciana de la metafísica como ontología (si bien esta última denominación técnica no es aún adoptada en las Disputationes) $[\ldots]^{11}$ la ratio de ente supremo (el ipsum esse subsistens o la causa universal del ser del que hablaba Tomás de Aquino) es reconducida en la ratio entis in quantum ens, según una precisa línea genealógica que parte de Avicena y, pasando por

6 Gilson, El ser y la esencia, op. cit., p. 132.

7 Gilson, El ser y la esencia, op. cit., p. 133.

8 Fernández Burillo, S., «Las disputaciones metafísicas de Francisco Suárez S.J., su inspiración y algunas de sus líneas maestras», Revista Española de Filosofía Medieval, 4 (1997), pp. 65-86, aquí p. 66.

9 Forlivesi, M., «Ontologia impura. La natura della metafísica secondo Francisco Suárez», en S. Castellote Cubells, Francisco Suárez. “Der ist der Mann”. Homenaje al prof. Salvador Castellote Cubells, Valencia, Facultad de Teología San Vicente Ferrer, 2004, pp. 161-207. Disponible en: http://web.tiscali.it/marcoforlivesi /mf2004oi.pdf, p. 26.

10 Poncela González, Á., «Presencia y disposición de las Disputationes Metaphysicae de Francisco Suárez en el proyecto ontológico-existenciario de Martin Heidegger», Veritas, 56/2 (2011), pp. 178-205, aquí p. 180.

11 Esposito, C., «Ens, essentia, bonum en la metafísica de Francisco Suparez», Azafea, 6 (2004), pp. 2947, aquí p. 33. 
Enrique de Gante y Duns Scoto, llega hasta Suárez (y, como sabemos, continuará también en autores modernos y contemporáneos $)^{12}$.

Aubenque entiende la metafísica de Suárez como ontología sobre la base de una línea de interpretación retrospectiva cuando declara: «Esta ciencia, convertida así en autónoma, puesto que es anterior y previa a la teología, bien merecerá a partir de entonces un nombre que le sea propio: este será el nombre de ontología, que aparecerá poco después en la escuela de Suárez o bajo su influencia» ${ }^{13}$. Barroso Fernández lo explica de la siguiente manera: «La metafísica toma así [en Suárez] un curso preponderantemente ontológico al pasar a ser su problema fundamental un problema objetivo-conceptual $[\ldots]^{14}$. El paso que ha de dar Suárez para la configuración de una ciencia ontológica independiente será el de subsumir a Dios dentro de la noción de ente en cuanto ente» ${ }^{15}$. En otro de sus textos argumenta: «Desde la interpretación ontologista ha sido habitual entender que Suárez ha dado lugar a una nueva noción de realidad entendida no desde el ámbito de la causación, sino desde el de la intención objetiva. En la perspectiva de Courtine, la clave de bóveda para pensar el giro efectuado por Suárez está en el carácter ontológicamente fundamental del extra nihil del aliquid respecto a su extra causas, es decir, respecto de su existir efectivo» ${ }^{16}$.

Ahora bien, la carga moderna del nombre ontología aplicado a las D.M. promueve el olvido de Suárez como intérprete desde sí mismo. Por ello, con vistas a despejar el equívoco de comprender la metafísica como ontología para acercarse adecuadamente a la tradición metafísica medieval en general y a las D.M. suarecianas en particular, cobra relevancia expresar la ciencia del ente en cuanto ente en los términos en que el mismo Dr. Eximio se refirió. En efecto, si los nombres de una ciencia imponen un horizonte de comprensión, e implican una hermenéutica particular de su objeto de estudio, se sigue que no hay inocencia alguna en el remplazo del nombre metafísica por aquel de ontología. Más aún, las referencias inmediatas contemporáneas a la metafísica suareciana suelen olvidar los nombres que aquella ciencia tuvo antaño, y con ello, inevitablemente, la reducción de las implicancias de lo que era su ámbito originario y los modos de relación de esa ciencia con las demás.

Hecha esta desvinculación de los títulos de ontología y ontoteología, parece más apropiado aproximarse a la doctrina suareciana desde su propio vocabulario y según el modo de pensar del Dr. Eximio, evitando así una reconfiguración innecesaria del horizonte de la ciencia metafísica propio del s. XVI.

\section{Dos introducciones al proemio de la metafísica}

Antecede a la D.M. I el motivo y el plan de toda la obra. Esta sección, que a su modo introduce también al lector cristiano (christiane lector) en las intenciones de Suárez, fija velozmente el lugar de la metafísica entre las ciencias desde una perspectiva personal o subjetiva. Aquí se dice: «Como es imposible que uno llegue a ser buen teólogo sin haber

12 Esposito, «Ens, essentia, bonum...», op. cit., p. 34.

13 Aubenque, P., «Suárez y el advenimiento del concepto de ente», Logos. Anales del Seminario de Metafísica, 48 (2015), pp. 11-20, aquí p. 19.

14 Barroso Fernández, «El objeto de la metafísica...», op. cit., p. 225.

15 Barroso Fernández, «El objeto de la metafísica...», op. cit., p. 227.

16 Barroso Fernández, Ó., «Los entes de razón en Suárez. Una concepción barrroca de la realidad», Anales del Seminario de Historia de la Filosofia, 28 (2011), pp. 135-161, aquí p. 139. 
sentado primero los sólidos fundamentos de la metafísica $[\ldots]^{17}$ o bien, «cada día, sin embargo, veía con claridad más diáfana cómo la Teología divina y sobrenatural precisa y exige ésta natural y humana [...] para restituir a la doctrina metafísica el lugar y puesto que le corresponde ${ }^{18}$.

Según el Dr. Eximio la metafísica está subordinada e inmediatamente sujeta a la teología. La ciencia divina mencionada en el texto se corresponde con aquella que es revelada, y que es mencionada por Suárez mediante su explícita intención de culminar su comentario a la Suma de Teología de Tomás de Aquino ${ }^{19}$. Empero, el modo propio de sujeción de la metafísica a la teología sobrenatural solo se esclarece párrafo más adelante cuando afirma: «de tal manera desempeño en esta obra el papel de filósofo, que jamás pierdo de vista que nuestra filosofía tiene que ser cristiana y sierva de la teología divina» ${ }^{20}$. Así Suárez adelanta en el plan de su obra que metafísica y teología divina o revelada son ciencias diferentes. Luego, la metafísica presta sus principios «para la confirmación de las verdades teológicas» ${ }^{21}$. Mas estos principios metafísicos son descubiertos únicamente a la luz de «los límites de la razón natural»»2

Suárez no ofrece argumentos objetivos sobre la subordinación de la metafísica a la teología revelada. Únicamente afirma la diferencia entre ellas y la sujeción epistémica de una a la otra. No separa ambas ciencias como si hubiera un núcleo epistémico que las mostrara como una y única. Reconoce que ambas son ciencias distintas donde cada una tiene un principio diferente. Y según ello, coloca la teología natural inmediatamente debajo de la teología sobrenatural. La metafísica, cuyas notas son el pensamiento racional, natural e independiente de la fe, descubre y establece unos determinados principios de carácter universal que rigen sobre las ciencias que le quedan sujetas, y también se vuelven útiles en orden a la mejor intelección de la teología divina. No sucede que la teología divina, ciencia sobrenatural y superior a la metafísica, dependa para su intelección de los principios metafísicos. Aquella teología es ciencia independiente porque tiene los suyos propios. Empero, tales principios, que son aquellos de la fe, se manifiestan de suyo oscuros para la razón cuando dicha facultad anímica no se ha ejercitado debidamente en el ámbito del pensar metafísico. La fe no ilumina por sí misma la metafísica. Aquella configura desde el comienzo otro ámbito, porque hace las

17 Suárez, D.M. Ratio et discursus totius operis.., p. 17: «Quemadmodum fieri nequit ut quis Theologus perfectus evadat, nisi firma prius metaphysicae iecerit fundamenta $[\ldots] »$.

18 Suárez, D.M. Ratio et discursus totius operis..., p. 17: «In dies tamen luce clarius intuebar, quam illa divina ac supernaturalis Theologia hanc humanam at naturalem desideraret [...] quo huic doctrinae mataphysucae suum quasi locum ac sedem darem, vel potius restituirem».

19 Cfr. Poncela González, Á., «Una aproximación bibliográfica a Francisco Suárez como comentador de la Suma Teológica», Cauriensia, 7 (2012), pp. 165-173.

20 Suárez, D.M. Ratio et discursus totius operis..., p. 17: «Ita vero in hoc opere philosophum ago, ut semper tamen prae oculis habeam nostram philosophiam debere christianam esse, ac divinae Theologiae ministram». Cfr. Espósito, C., «Suárez: filósofo barroco», Cauriensia, 12 (2007), 25-42, aquí pp. 34-35: «Lo más relevante en este contexto es que el «personaje» que entra en escena es el filósofo, pero el «intérprete» es el teólogo. El motivo de esta representación residía en el convencimiento de que no se puede ser buen teólogo sin base metafísica». Sobre una breve comparación del prólogo con otras obras de F. Suárez cuya interpretación no difiere sustancialmente de aquella de C. Espósito, cfr. González, Á.L., La intermediación de filosofía y teología: Santo Tomás de Aquino, San Buenaventura, Nicolás de Cusa, Suárez, Cuadernos de Anuario Filosófico, Pamplona, 2011, pp. 89-105.

21 Suárez, D.M. Ratio et discursus totius operis..., p. 18: «ad Theologicas veritates confirmandas referenda et accommodanda».

22 Suárez, D.M. Ratio et discursus totius operis..., p. 18: «deinde quod mihi nunquam visus sum luminis naturalis, atque adeo nec metaphysicae, limites transilire». 
veces de fundamento de la ciencia de la teología revelada. A su vez la metafísica tiene un límite subjetivo. Es la máxima ciencia humana alcanzable por la razón -los límites de la razón natural- sobre la cual no hay ninguna otra. La metafísica establece los límites del pensar humano mediante el descubrimiento de sus propios principios máximamente universales y es, simultáneamente, apertura a la teología revelada. Solo así se explica la expresión de Suárez «es imposible que uno llegue a ser buen teólogo sin haber sentado primero los sólidos fundamentos de la metafísica».

Ahora bien, aquellos fundamentos de la teología natural dependen de una esmerada investigación metódica ${ }^{23}$ que colabora en la configuración de la metafísica respecto de sí misma. Y así, una metafísica perfecta coloca el basamento necesario para una buena teología, mientras que una metafísica endeble sienta las bases de una teología inadecuada. La intención de Suárez de ser un buen teólogo -y, extensivamente, de que haya una buena teología- parece señalar la ausencia de una formación metafísica y teológica propia de la época. No se trata de la ausencia absoluta de tales estudios. Claramente no es el caso. Antes bien, señala la inconformidad del jesuita respecto de tales estudios ${ }^{24}$.Y esto sí es manifiesto de modo inmediato en las seis opiniones de lo que debería ser la metafísica, contenidas todas ellas en la sección primera de la D.M. I. A este respecto el Dr. Eximio añadía: «cada día, sin embargo, veía con claridad más diáfana cómo la Teología divina y sobrenatural precisa y exige ésta natural y humana». Aquí se visualiza la recepción anhelada de la teología divina respecto de los principios de la metafísica. De modo que, viendo en la ciencia de la razón una apertura, notamos también una recepción rectamente querida de la ciencia de la fe. Y es rectamente querida, porque se pretende una buena teología que se logra solo mediante una metafísica sólidamente fundamentada.

En esta mutua colaboración de saberes Suárez se lamenta de la situación de la metafísica y se propone restituirle «el lugar y puesto que le corresponde» ${ }^{25}$. Frase que debe ser leída de la siguiente manera: reconociendo la minusvalía e indecorosa situación de la filosofía primera, se vuelve patente que la única manera de lograr que ella recupere su sitio depende de centrar la racionalidad humana en su tarea más propia. Que ella, y sólo ella sin aceptar ayuda de la fe, dé su máximo esfuerzo en la exploración de su objeto adecuado. En orden a la realización de tal tarea, se explora el ente «en su máxima extensión y universalidad con sus propiedades y causas ${ }^{26}$ mediante una razón metódicamente conducida que provoca el surgimiento de los principios metafísicos, todos ellos, a su vez, dispuestos para la tarea de la teología divina. De ahí que la consideración del objeto adecuado de la metafísica se aborde, en primer lugar, desde los nombres de esta ciencia -en tanto orientan el pensar metafísico- y seguidamente, en la tarea de despejar equívocos las seis opiniones diferentes en las D.M. I de lo que debería ser la metafísica. Una vez acometidas las instancias mencionadas, la ciencia máxima de la razón logrará recuperar lo que le pertenece: ser la ciencia humana superior y regente de las restantes.

23 Suárez, D.M. Ratio et discursus totius operis..., p. 18: «et quoniam iudicavi semper magnam ad res intelligendas ac penetrandas, in eis conveniente método inquirendis et iudicandis $[\ldots] »$. 167-194.

24 Cfr. Gomez-Arboleya, E., «Suárez y el mundo moderno», Revista Nacional de Educación, 3 (1943),

25 Para una expresión similar sobre el deterioro de la ciencia metafísica, cfr. Kant, I., Crítica de la razón pura, trad. y notas de P. Ribas e intr. de J. L. Villacañas, Gredos, Madrid, 2010. Prólogo a la segunda edición, B XIV, p. 19.

26 Suárez, D.M. Ratio et discursus totius operis..., p. 18: «Deinde, in priori tomo eiusdem obiecti amplissima et universalissima ratio, quae, videlicet, appellatur ens, eiusque proprietates et causae diligenter expenduntur». 


\section{Los nombres de las ciencias señalan la naturaleza epistémica de sus objetos}

Sobre las dos tareas anunciadas para que la ciencia metafísica recupere «el lugar y puesto que le corresponde» nos detenemos únicamente en la primera. El motivo de la obra adelanta, en cierto modo, el contenido del proemio de la D.M. I donde se tratan los nombres de la metafísica, y sólo después se ocupa de argumentar en contra de las opiniones sobre la configuración y las tareas de dicha ciencia.

La disputación primera lleva por título 'la naturaleza de la filosofía primera o metafísica'. Aquí se adelantan los nombres más adecuados a este saber y la búsqueda del sustento de dichos títulos mediante la expresión 'naturaleza'. En efecto, es un tratado sobre filosofía primera o metafísica, y conviene esclarecer, es más correcto en cierto modo el nombre de filosofía primera por dos razones. Porque no hay ciencia humana, natural y racional superior a ella, y porque tal título expresa también los principios por los que se establece, por un lado, la vinculación científica con los ciencias segundas, y por el otro, con la teología sobrenatural. Este nombre ya se adelantaba, por su funcionalidad, en el plan de toda la obra y se precisa con suficiente evidencia en el proemio a las D.M.:

Aunque la teología divina y sobrenatural se apoya en la divina iluminación y principios revelados por Dios, supuesto que se ha de completar con el discurso y raciocinio humano, se ayuda también de las verdades conocidas por la luz natural, y de ellas usa como de instrumentos y ministros para llevar a término sus razonamientos e ilustrar las divinas verdades. Pero entre todas las ciencias naturales, aquella que ocupa el primer lugar y obtuvo el nombre de filosofía primera, es la que principalmente ayuda a la teología sobrenatural; ya porque es la que más se acerca al conocimiento de las cosas divinas, ya también porque es ella precisamente la que explica y confirma los principios naturales que abarcan todas las cosas y que, en cierto modo, sustentan y mantienen toda ciencia ${ }^{27}$.

La doble vinculación de la filosofía primera con la teología sobrenatural y las restantes ciencias subalternas aparece aquí explicitada. Empero, la ayuda prestada de la filosofía primera a la teología divina no significa la dependencia de esta última respecto de la anterior, antes bien, por la proximidad entre ambas debe entenderse que «se hallan de tal forma trabadas estas verdades y principios metafísicos con las conclusiones y discursos teológicos, que si se quita la ciencia y perfecto conocimiento de aquellas, tiene necesariamente que resentirse también en exceso el conocimiento de éstas» ${ }^{28}$.

El proemio general a las D.M. ha puntualizado el modo en el que la metafísica colabora con la teología sobrenatural. También ha colocado las bases para comenzar una exploración del objeto adecuado de la filosofía primera. Y así, la consideración del ente en cuanto ente real, separado de la teología revelada, y explorado por la teología natural, debe comenzar,

27 Suárez, D.M. proemio..., p. 203: «Divina et supernaturalis theologia, quamquam divino lumine principiisque a Deo revelatis nitatur, quia vero humano discursu et ratiocinatione perficitur, veritatibus etiam naturae lumine notis iuvatur, eisque ad suos discursus perficiendos, et divinas veritates illustrandas, tamquam ministris et quasi instrumentis utitur. Inter omnes autem naturales scientias, ea quae prima omnium est et nomen primae philosophiae obtinuit, sacrae ac supernaturali theologiae praecipue ministrat. Tum quia ad divinarum rerum cognitionem inter omnes proxime accedit, tum etiam quia ea naturalia principia explicat atque confirmat, quae res universas comprehendunt omnemque doctrinam quodammodo fulciunt atque sustentant».

28 Suárez, D.M. proemio..., p. 204: «Ita enim haec principia et veritates metaphysicae cum theologicis conclusionibus ac discursibus cohaerent ut si illorum scientia ac perfecta cognitio auferatur, horum etiam scientiam nimium labefactari necesse sit». 
según antes se dijo, por los nombres y tareas de la metafísica, figurados todos ellos en el prólogo a las D.M. 1. Veamos esto con mayor detenimiento:

Para comenzar, como es debido, por el nombre, son varios los impuestos a esta doctrina, parte tomados de Aristóteles, parte de otros autores. En primer lugar ha sido llamada Sabiduría -lib. I Met., c. 2- puesto que disputa acerca de las primeras causas de las cosas, y de las cosas superiores y más difíciles y, en cierto modo, sobre todos los entes ${ }^{29}$.

La razón de los nombres de una ciencia responde a una concepción que da cuenta del significado del mismo según el subiectum del que tratan. El desenvolvimiento de la noción de sabiduría depende, en consecuencia, de dos cuestiones mutuamente trabadas sobre las que se apoyan las demás consideraciones: las nociones de disputare y de entes. Esta es la clave de lectura. Disputar acerca de algunos entes es debatir sobre los considerandos de las ciencias subordinadas. En cambio, considerar todos los entes reales en lo que tienen de común -y tangencialmente las razones por las cuales no se consideran los entes de razón- no es tarea sencilla, antes bien, es debatir «acerca de las cosas superiores»-razón por la cual recibe el nombre de ciencia suprema- «y acerca de las más difíciles» -porque no hay acuerdo sobre el modo de considerar la totalidad de los entes en común como objeto adecuado de este saber, lo que de suyo se sigue necesariamente de las cosas que son superiores- . Ahora bien, lo superior, por su máxima extensión y profundidad, es la ciencia del ente en cuanto ente real, y por ello se la llama sabiduría, porque no sólo conoce la totalidad, sino incluso sabe acerca de ella totalmente. No solo sabe del todo, sino que sabe los argumentos sobre los cuales el todo o ente en cuanto ente real está fundado. Y ello es afirmar la búsqueda de las primeras causas de las cosas. El debate sobre las razones de todos los entes $-\mathrm{v}$.g. las discusiones sobre las diferentes concepciones de la metafísica de la sección primera- pone de manifiesto los diferentes argumentos sobre el fundamento de la metafísica. De modo que, una vez afirmada la metafísica como ciencia que estudia el ente en cuanto ente real, es necesario conocer las causas por las cuales los considera. Y así, si las causas o principios de todos los entes aparecen claras ante el pensar, entonces la metafísica será una ciencia sólidamente fundada que habrá recuperado el lugar y puesto que le corresponde entre las ciencias especulativas. De donde, una vez cumplida esta finalidad, se seguiría también la apertura hacia la teología revelada y la posibilidad de la existencia de una buena teología, fin último al que todo el tratado de la metafísica se extiende.

Ni importa para esto el que en el lib. I de la Metafísica se la llame Prudencia, ya que se le aplica este nombre no con propiedad, sino por una cierta analogía, pues de la misma manera que en el orden práctico es la prudencia lo que ha de ser más buscado, así en el especulativo lo ha de ser esta sabiduría ${ }^{30}$.

Sabiduría es el nombre de la filosofía primera de acuerdo con el conocimiento asimilado, y no la erudición e información acerca de algo. Saber sobre el ente en cuanto ente es dar cuenta

29 Suárez, D.M. 1.., p. 207: «Ut a nomine, ut par est, sumatur exordium, varia sunt nomina, partim ab Aristotele, partim ab aliis auctoribus, huic doctrinae imposita. Primo enim appellata est sapientia, I Metaph., c. 2 , quoniam de primis rerum causis, et supremis ac difficillimis rebus, et quodammodo de universis entibus disputat».

30 Suárez, D.M. 1..., p. 207: «Nec refert quod I Metaph. prudentia appelletur; id enim cognomen non proprie, sed per analogiam quamdam illi accommodatum est; quia sicut in practicis prudentia, ita in speculativis haec sapientia maxime expetenda est». 
de ello de modo efectivo y verídico, pues el fin de toda ciencia es la verdad y sus razones deben ser auténticamente demostrativas. Esta es la sabiduría acerca del todo o ente en cuanto ente. Y saber acerca del ente simpliciter es más propio del ámbito especulativo que del práctico, orientado, en efecto, hacia el hacer. De este modo la prudencia se presenta con el nombre de la sabiduría, en tanto que ella es, por analogía, su nombre en el orden práctico. Los nombres metafísicos son títulos en el ámbito de lo especulativo. De modo que el nombre de prudencia no aplica con propiedad sobre la ciencia metafísica mientras que aquel otro de sabiduría lo hace desde la singularidad de la persona que sabe acerca del ente en cuanto ente.

En segundo lugar, se la llama también absolutamente, y como por antonomasia, Filosofía -lib. IV met., texto 5- en donde también se la llama Filosofía Primera -en el texto 4, y en el lib. VI, texto 3-, pues siendo la filosofía el afán por la sabiduría, este afán debe ser adquirido en gran manera para esta ciencia dentro del orden natural, puesto la misma sabiduría también se ocupa del conocimiento de las cosas divinas ${ }^{31}$.

Hasta ahora el primer nombre de la metafísica es sabiduría, mientras que el otro de prudencia queda subsumido en el primero. El segundo título será aquel de filosofía, pues dice: «en segundo lugar se la llama [...]». Empero sucede aquí un caso similar al título de sabiduría. Suárez no separa la explicación del nombre filosofía de aquel otro de filosofía primera. La distinción entre ambos es meramente nominal, no de sentido. En efecto, filosofía o filosofía primera es el afán subjetivo por alcanzar la anhelada sabiduría en el orden natural. Al título de sabiduría, que trata acerca del ente todo o ente en cuanto ente en su máxima extensión y comprensión según el orden natural, racional y no revelado, se añade el impulso vital de transitar hacia él. Esta es la filosofía, donde el camino hacia la sabiduría es también sabiduría, porque el mismo nombre de filosofía es camino sapiencial. La sabiduría se dice filosofía a causa del compromiso vital del ser humano con la ciencia máxima de la razón natural en virtud de la comprensión del ente en su totalidad. Este es su dominio propio y su límite en lo que atañe a la racionalidad humana. De ahí que, una vez comprendido el ente en cuanto ente, la filosofía podrá quedar al libre servicio de la teología revelada. Aquí se presenta un movimiento simultáneo de (1) clausura, en tanto límite racional respecto de la comprensión del ente en cuanto ente, y (2) apertura de la sabiduría humana hacia la revelación sobrenatural. Según ello, queda manifiesto que la fe no ilumina la metafísica, sino que constituye de suyo el ámbito de una ciencia diversa. Teología revelada y metafísica son ciencias diferentes que no necesitan ser separadas porque ya así se presentan.

En la definición que ofreció Francisco Suárez sobre sabiduría se decía: «las primeras causas de las cosas, y de las cosas superiores y más difíciles». Una de las direcciones hermenéuticas de dicha expresión fue aquella del ente en cuanto ente. Lo más difícil y superior es comprender qué es el ente en su totalidad, lo que también debe entenderse como la existencia de entes determinados que son causa de otros. Ahora bien, el hecho de que algunos entes son causa de otros también guarda relación con la nueva tarea anunciada por el intelectual jesuita. La filosofía es camino de sabiduría natural y racional, y también es culminación en la medida en que logre hacer sabio al hombre. Esta sabiduría consiste, incorporando la tarea previa, en «el conocimiento de las cosas divinas». Pero ello solo es posible porque la consideración de

31 Suárez, D.M. 1..., p. 207: «Deinde dicitur absolute et quasi per antonomasiam philosophia, IV libro Metaph., text. 5, ubi etiam text. 4, et lib. VI, text. 3, prima philosophia nominatur; est enim philosophia studium sapientiae: hoc autem studium intra naturae ordinem in hac scientia acquirenda maxime adhibetur, cum ipsa sapientia sit et in divinarum rerum cognitione versetur». 
todos los entes incluye necesariamente aquella tarea del conocimiento de lo divino. Conocer la existencia de lo divino desde la metafísica implica la necesaria vinculación causal entre la totalidad del ente contingente y el ente absolutamente necesario que lo ha producido. Aquí no hay ente real que quede fuera de la consideración de todos los entes, cumpliéndose, al quedar incluida esa precisa ocupación, la fórmula de la totalidad: ente en cuanto ente.

De aquí que también sea llamada Teología Natural -lib. VI de la Met., c. 1 y lib. XI, c. 6- ya que estudia a Dios y las cosas divinas en cuanto es posible con la luz natural; por ello ha sido llamada también Metafisica, no ya por Aristóteles sino por sus intérpretes, tomándolo del título que el mismo Aristóteles antepuso a sus libros de Metafísica, a saber, $\tau \dot{\alpha} \mu \varepsilon \tau \dot{\alpha} \tau \dot{\alpha} \varphi v \sigma \iota \kappa \alpha ́$, es decir, acerca de aquellas cosas que vienen a continuación de las ciencias o cosas naturales. Prescinde, pues, esta ciencia de las cosas sensibles o materiales (que se denominan físicas, porque de ellas se ocupa la filosofía natural), y considera las cosas divinas y separadas de la materia, y las razones comunes del ente que pueden existir sin la materia, y por ello es llamada Metafisica, como colocada después o más allá de la física. Y digo después no en cuanto a la dignidad, o según el orden de la naturaleza, sino por el orden de adquisición, generación o invención. Y si queremos entender esto desde el objeto mismo, se dice que las cosas de que trata esta ciencia están después de los entes físicos o naturales, porque superan el orden de estos y están colocados en un orden de realidades más elevado ${ }^{32}$.

La ciencia de la filosofía primera -llamada también simplemente filosofía- trata afanosamente acerca del ente en cuanto ente, lo que implica también disputar acerca de las cosas divinas, y más precisamente, de Dios. Esta es la sabiduría de dicha ciencia. Los nombres precisan cada vez más la tarea de la metafísica. La noción transversal a cada uno de ellos es el primero de sus títulos: la sabiduría en su doble condición de movimiento y culminación de ella misma. Tratar acerca de las cosas divinas es propio de la filosofía primera, y por esta razón recibe también el nombre de teología natural, porque «estudia a Dios y las cosas divinas en cuanto es posible con la luz natural». Tal expresión, adelantada en el plan de la obra en la modalidad de «bajo los límites de la razón natural» significa la posibilidad de debatir hasta fijar doctrina en los temas de esta ciencia, ya que es el deseo de Suárez poner de manifiesto una metafísica razonablemente perfecta y de una lógica coherente con vistas a una buena teología sobrenatural. El interés del jesuita está en alcanzar una metafísica acerca de Dios y la realidad divina de modo exclusivamente racional y natural, ausente de fe, y simultáneamente compatible con el dato revelado en la ciencia de la teología sobrenatural, al modo como es considerada por el cristianismo. Y todo ello de acuerdo con el modo de pensar de Tomás de Aquino en su Suma de Teología.

32 Suárez, D.M. 1..., pp. 207-208: «Hinc rursus naturalis theologia vocatur ex lib. VI Metaph., c. 1, et lib. XI, c. 6, quoniam de Deo ac divinis rebus sermonem habet quantum ex naturali lumine haberi potest; ex quo etiam metaphysica nominata est, quod nomen non tam ab Aristotele, quam ab eius interpretibus habuit; sumptum vero est ex inscriptione quam Aristoteles suis Metaphysicae libris praescripsit, videlicet: $\tau \hat{\alpha} \mu \varepsilon \tau \grave{\alpha} \tau \hat{\alpha}$

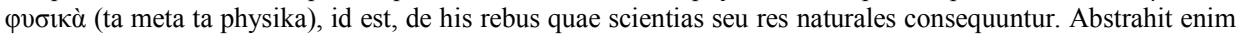
haec scientia a sensibilibus seu materialibus rebus (quae physicae dicuntur, quoniam in eis naturalis philosophia versatur), et res divinas et materia separatas, et communes rationes entis, quae absque materia existere possunt, contemplatur; et ideo metaphysica dicta est, quasi post physicam, seu ultra physicam constituta; post (inquam) non dignitate, aut naturae ordine, sed acquisitionis, generationis, seu inventionis; vel, si ex parte obiecti illud intelligamus, res de quibus haec scientia tractat dicuntur esse post physica seu naturalia entia, quia eorum ordinem superant, et in altiori rerum gradu constitutae sunt». 
La ciencia de la teología natural recibe el nombre de metafísica por dos razones. En primer lugar según su fin, porque disputa -según la acepción de sabiduría- acerca de Dios y las cosas divinas mediante el uso de la razón. Seguidamente, porque lo hace después de considerar la ciencia de las cosas sensibles. Esta segunda acepción del término 'metafísica' apunta a su origen, y es ponderada con sumo cuidado por el mismo Suárez. No se limita a afirmar que la ciencia de la metafísica está «colocada después o más allá de la física». Añade una breve explicación sobre el ámbito y el límite de la ciencia física y el modo en que aparece la metafísica. En efecto, el enlace epistémico entre la teología natural y la física gravita en la noción «a continuación o después de,» lo que no puede simplemente interpretarse como una construcción temporal. En efecto, si la ciencia física, o filosofía natural, trata acerca de los entes sensibles o materiales ${ }^{33}$, no se sigue lógicamente que después de ella aparezca la metafísica disputando sobre aquellos entes separados de materia, sino porque se los considera divinos. Si Suárez dijera sin más que la metafísica trata sobre los entes sin materia, ello no sería razón suficiente para ubicarla después de la física. La filosofía natural no es primera porque trate de los entes sensibles y materiales y la filosofía primera no es posterior a ella porque trate de los entes inmateriales. La razón de la relación entre ambos saberes depende de su nexo con el hombre, ya que «digo después no en cuanto a la dignidad, o según el orden de la naturaleza, sino por el orden de adquisición, generación o invención». La ciencia física es primera para nosotros, porque así la descubrimos -ordo inveniendi- y consecuentemente, la adquirimos. Así la filosofía natural, que trata de los entes materiales y sensibles, es anterior y primera para nosotros, mientras que la filosofía primera o metafísica es segunda para nosotros o posterior, ya que solo -ahora sí- la descubrimos después de la física. Empero, el tratamiento del ente en cuanto ente podría ser mera elucubración abstracta sin realidad entitativa. Llegados a este núcleo sólo adelantamos que dicha situación es resuelta aquí anticipadamente -cuestión tratada en parte en las opiniones I y II de la sección primera- mediante la inclusión de la expresión «las cosas divinas, y Dios» cuestión matizada en la opinión III. De esta manera Suárez muestra de modo efectivo que la metafísica no es un estudio ficcional de todos los entes, sino real, por referir lo divino, y por la misma razón, también, superior a la física.

Antes afirmamos que no podría entenderse correctamente la relación de ubicuidad entre física y metafísica simplemente desde una ponderación temporal, donde la filosofía natural es anterior y la metafísica posterior. Tales adverbios de tiempo tienen razón de ser cuando aparecen enraizados en un núcleo de sentido, que es el hombre. Solo por medio de él se explica satisfactoriamente la aplicación de lo anterior y lo posterior a ambas ciencias. Ahora bien, esta clave antropológica es completada con otra cuando el Granadino destaca: «y si queremos entender esto desde el objeto mismo, se dice que las cosas de que trata esta ciencia están después de los entes físicos o naturales, porque superan el orden de estos y están colocados en un orden de realidades más elevado». Luego, de sus palabras se sigue, no la clave antropológica, que es primera quoad nos, sino aquella de la naturaleza de los entes donde lo anterior y lo posterior aparecen en una dimensión diferente. La naturaleza en su totalidad consta de niveles de perfección donde algunos entes son más perfectos que otros. La física indaga el

33 Cfr. García de la Sienra, A., «La sustancia material en Suárez», Tópicos, 21 (2001), pp. 9-26. Cfr. Prieto López, L.J., «La impronta escotista en la metafísica de Suárez: conocimiento intuitivo, actualidad de la materia prima e hipostatización del accidente», Logos. Anales del Seminario de Metafísica, 50 (2017), pp. 207-227, aquí p. 214: «[Con el nominalismo a través de Suárez] se propiciará una nueva actitud teórica frente a las realidades naturales, en las que los aspectos empíricos y medibles primarán sobre las dimensiones inteligibles del ente. Este nuevo acercamiento al estudio de los entes naturales dará origen a la ciencia moderna de la naturaleza». 
ámbito de la naturaleza de los entes sensibles o materiales. Y por la naturaleza de tales entes esa ciencia es inferior y menos perfecta que la metafísica, porque esta última se restringe a la naturaleza de todos los entes. Se unen así ambas claves. Lo que es de naturaleza inferior es primero por naturaleza para el hombre, y lo que es perfecto por naturaleza es posterior para el hombre. La metafísica trata de un orden natural, inmaterial y divino. Su carácter divino manifiesta lo inmaterial como superior. Empero la simple característica de inmaterial no es razón suficiente para la superioridad de estos entes en comparación con aquellos entes de naturaleza física.

La explicación del origen de la ciencia metafísica señalada en el párrafo precedente está sujeta para su comprensión a la razón de finalidad. El argumento de procedencia, que es el segundo dado por Suárez, está subordinado al argumento teleológico, que es el primero. En efecto, la ciencia metafísica trata de las cosas divinas y de Dios, y a causa de ello aparece más claramente para la razón una explicación del origen de la sabiduría natural. Después de tales consideraciones, Suárez menciona el último nombre asignado a la metafísica. Allí se dice:

Y por ello, finalmente, ha sido también llamada esta ciencia Princesa y Señora-lib. VI Met., c. 1, y lib. XI, c. 6- porque aventaja en dignidad a las restantes ciencias, y de algún modo establece y confirma sus principios ${ }^{34}$.

Cuando en el texto se dice «y por ello» se significa el «orden de realidades más elevado» concerniente a la tarea metafísica. La misma concepción se repite al afirmar: «aventaja en dignidad a las restantes ciencias». Ahora bien, así como Suárez mostró el tránsito del nombre 'filosofía primera' a aquel de 'metafísica', así muestra, ahora, el mismo movimiento desde el nombre 'metafísica' a aquel otro de 'princesa y señora', cuya particularidad está en lo siguiente: «y de algún modo establece y confirma sus principios». Luego el último nombre de la ciencia de la sabiduría cierra especulativamente el proemio aquí expuesto sintetizando la fuerza regente de dicha ciencia sobre las demás. Dar a la metafísica el nombre de 'princesa y señora' confirma aquel de (1) sabiduría, llamada también por analogía (2) prudencia. Refleja los otros títulos de (3) filosofía o (4) filosofía primera, y de (5) teología natural. Cada uno de ellos dice la noción de sabiduría desde el comienzo, cuya precisión incorpora siempre los nombres precedentes. La noción de sabiduría, al ser transversal a cada uno de los nombres restantes, es el título de máxima extensión que se concreta en cada caso con un título distinto, poniendo al descubierto alguna singularidad.

Decir sabiduría como princesa y señora es llamar a la metafísica ciencia suprema racional, descubierta última por el hombre siendo primera por naturaleza. Esta primacía se observa en su regencia, que no es despótica, antes bien, máximamente libre y respetuosa de la constitución de las demás ciencias, porque se dice en el texto: "de algún modo confirma». Cada ciencia tiene sus propios principios válidos con los cuales rige su saber. Pero los principios de las ciencias inferiores -v.g. la física y la matemática- no son indiferentes a los principios de la metafísica en razón de tal confirmación, poniéndose al descubierto la necesaria y libre vinculación que debe existir entre las ciencias. El nombre de 'princesa y señora' manifiesta el surgimiento de un orden de ciencias que Suárez tratará en diferentes ocasiones a lo largo del tratado de la metafísica ${ }^{35}$. El Dr. Eximio añade que la metafísica «de algún modo establece»

34 Suárez, D.M. 1..., p. 208: «Ex quo tandem appellata est haec scientia aliarum princeps et domina, VI Metaph., c. 1, et lib. XI, c. 6, quod dignitate antecellat, et omnium principia aliquo modo stabiliat et confirmet». 35 Cfr. Suárez, D.M. 1..., Sec. V, n. 46. 
los principios de las demás ciencias. Aquí está el matiz de la libertad en la constitución de los diferentes saberes. No dice que la metafísica le dicta y otorga los principios a las demás ciencias, ya que si así fuere, la distinción entre ellas sería más nominal que real. La expresión suareciana «de algún modo» marca el nexo especulativo entre la ciencia de la sabiduría y las otras, ponderando el hecho de que la compatibilidad hallada es posible porque los principios de la metafísica hacen las veces de principios seminales para las restantes. Esta lectura muestra los principios de la filosofía primera como máximamente universales en razón de su aplicación a todos los saberes de modo diferente, en tanto depende de la ciencia inferior que se considere.

Todos estos nombres se han tomado de la materia u objeto sobre aquello que versa esta doctrina, tal como fácilmente puede verse por las interpretaciones y motivos de los mismos. En efecto, suelen los sabios, como enseñó Platón en el Crátilo, imponer el nombre a las cosas después de considerar su naturaleza y dignidad; y como la naturaleza y dignidad de una ciencia depende principalmente de su objeto, es necesario investigar primeramente el objeto de esta doctrina o su subiectum y, conociendo éste, fácilmente se hará patente cuáles sean sus funciones, cuál su necesidad o utilidad y cuán grande su dignidad ${ }^{36}$.

Estas son las últimas palabras del proemio a la metafísica del jesuita Francisco Suárez. Ellas señalan con suficiente claridad que todo nombre dado a una ciencia $-\mathrm{v}$. g. aquella que estudia el ente en cuanto ente recibe el título de metafísica, filosofía primera, teología natural, etc.- está tomado del subiectum u objeto del cual trata. La realidad y la naturaleza del subiectum es la que provoca el nacimiento de un nombre específico para cada saber. Por este motivo el título impuesto a una ciencia no obedece a una arbitrariedad subjetiva sino a la naturaleza del ente considerado, ya en cuanto ente (metafísica), o en cuanto material y sensible (física), o de otro modo, puesto que ello es lo que significa cada ciencia. Y así, de la naturaleza del ente que se considere emerge tanto la naturaleza de la ciencia cuanto su dignidad. En el caso de la metafísica los nombres son inclusivos y cada vez más precisos. No se oponen ni se eliminan ni tampoco puede añadirse otro diferente. Las dos primeras afirmaciones son claras, mientras que la última se legitima en el pensamiento de Suárez y en la tradición de la que es deudor. Por último, investigar el objeto de la doctrina metafísica no implica oposición con las tareas o el ámbito de dicha ciencia. Sus nombres ya dicen cuál es el objeto de la mentada ciencia, cuál su función, su dignidad y su necesidad. Lo que el Dr. Eximio añade aquí es la importancia de detenerse en la ciencia de la sabiduría en cuanto tal, y que solo ha sido al momento presentada como introducción especulativa.

\section{Consideraciones finales}

Una detenida hermenéutica del proemio a la D.M. 1 de Francisco Suárez colabora con la comprensión de la totalidad de esta obra del siguiente modo: los nombres de la metafísica exigen de la persona una férrea formación intelectual comprometida con un esmerado modo

36 Suárez, D.M. 1.., p. 208: «Haec autem universa nomina ex obiecto seu materia circa quam haec doctrina versatur, sumpta sunt, ut ex eorum rationibus et interpretationibus facile constare potest. Solent enim a sapientibus unicuique rei nomina imponi, spectata prius cuiusque natura et dignitate, ut Plato in Cratilo docuit; uniuscuiusque autem scientiae natura et dignitas ex obiecto potissimum pendent, et ideo primum omnium inquirendum nobis est huius doctrinae obiectum seu subiectum, quo cognito, constabit facile quae sint huius sapientiae munera, quae necessitas vel utilitas, et quanta dignitas». 
de vida ordenado a la virtud de la sabiduría, y no sólo una discusión erudita e informativa sobre el ente en cuanto ente. De acuerdo con ello, sus siete nombres muestran tanto la amplitud y el límite del ámbito metafísico en relación con su objeto adecuado y procedencia, cuanto la sujeción natural y libre, por un lado, de la máxima ciencia racional a la sabiduría revelada, y por el otro, la dependencia libre y natural de las demás ciencias respecto de la metafísica.

Los títulos de la metafísica ponen en evidencia una riqueza de contenido manifestada (1) en sí misma por sus tareas propias, (2) en la regencia sobre las otras ciencias, y (3) en la subordinación inmediata a la teología revelada que los nombres de ontología y ontoteología decididamente no transparentan.

La metafísica de Suárez se presenta así más medieval que moderna por su nombre, por sus títulos, por su modo de abordaje en disputas y por las autoridades mencionadas. Empero su medievalidad es barroca y renacentista, y no se corresponde directamente con las glosas a la metafísica de la escolástica precedente ${ }^{37}$, entre las cuales descuella aquella de Tomás de Aquino. De manera que si volvemos una vez más al plan de la obra de la metafísica de Suárez advertimos que su seguimiento del fraile dominico ${ }^{38}$ es sui generis, lo que deja verse palmariamente en la diferente concepción que tienen por ejemplo el Aquinate y el Dr. Eximio de la filosofía. En lo que toca a esta cuestión podemos advertir en Suárez un movimiento especulativo ilegítimo, o al menos infundado, que buscaría reconocer en Tomás de Aquino, sino explícita al menos intencionalmente, la expresión 'filosofía cristiana' como validación de su modus ratiocinandi. Y ante ello corresponde aclarar que el Aquinate jamás se valió del término 'filosofía cristiana' ${ }^{39}$ para promover un modo de compatibilización entre la filosofía y la fe revelada.

37 Cfr. Filippi, S., «La restitución de valor inteligible al conocimiento sensible en el realismo medieval», Scripta Mediaevalia, 3/2 (2010), pp. 29-66, aquí pp. 44-45: «Y es que, pese a su intento por continuar la tradición escolástica, el contexto en que Suárez piensa ha variado sustancialmente. Después del Concilio de Trento (1545-1563) se hacía necesario repensar las razones de la teología católica a fin de enfrentar la crítica de los reformadores. En tal clima, Tomás de Aquino era el autor menos grato a la teología protestante, sobre todo, a causa de la idea de que se pudiese llegar mediante la razón natural a un cierto conocimiento acerca de Dios partiendo de la experiencia sensible. En un horizonte de pensamiento en que la fe y la razón se separaban crecientemente, el mundo natural resultaba cada vez más inaceptable para una aproximación racional a Dios. Entre la realidad natural y Dios hay un abismo que ya no se puede salvar. A partir de aquí, la metafísica parece destinada a abandonar el «naturalismo» aristotélico que permitía un amplio pasaje entre el ámbito de la física y el de la teología natural, para trasladarse al ámbito de lo puramente suprasensible, esta vez, en el sentido de lo formalmente abstracto, distante de la experiencia sensible y progresivamente fundado en un a priori lógicoconceptual. La misma Escolástica precedente, especialmente con Duns Escoto, había dado ya algunos pasos en esa dirección. Tanto que, aunque Suárez con frecuencia parece seguir en la letra a Tomás, de hecho sigue a Escoto».

38 Cfr. Aubenque, «Suárez y el advenimiento...», op. cit., p. 12: «La innovación es disimulada por el mismo Suárez, que se reclama constantemente parte de los autores anteriores, particularmente de Santo Tomás; pero la innovación es real y, de hecho, manifestará su fuerza y su irreversibilidad en los efectos que producirá.» Cfr. Prieto López, «La impronta escotista en la metafísica de Suárez...», op. cit., p. 210: «Reconocer que las metafísicas de Tomás de Aquino y Suárez son profundamente distintas, porque parten de principios muchas veces no solo distintos, sino incluso opuestos, precisamente en la medida que Suárez se inspira frecuentemente en Escoto. Suárez es un aristotélico y un tomista sui generis».

39 Cfr. Mendoza J.M.F., «Tomás de Aquino y la filosofía: una interpretación de su comentario al lib. 1, q.1, a.1 de las sentencias lombardinas» Azafea, 19 (2017), pp. 201-219. Cfr. idem, «Una glosa al texto de Tomás de Aquino De Trinitate I, Q. 2, A. 3: Agustín de Hipona y los alcances de la filosofía en la Sacra Doctrina», Opúsculo filosófico, 9/ 27 (2016), pp. 13-45. Cfr. idem, “Tomás de Aquino y la relación entre filosofía y 
Quizá por esta razón la expresión 'filosofía cristiana' ${ }^{40}$ utilizada por Suárez -cuyo contenido fundamental es la exégesis de los temas de la Metafísica de Aristóteles- intente promover, paradójicamente, tanto una lectura cristiana cuanto neutra de la metafísica. Según esta clave de bóveda se insistiría en pensar desde una óptica cristiana a Aristóteles sin el concurso directo de la fe, lo que se notará en capítulos posteriores cuando el Dr. Eximio busque resolver el modo de la presencia del Dios cristiano en su doctrina metafísica desde una comprensión del ente como conceptus entis ${ }^{41}$ y no como habens esse.

José María Felipe Mendoza

josefelipemendoza@hotmail.com

Fecha de recepción: 30/07/2018

Fecha de aceptación: 27/10/2018

teología: una interpretación literal de la Suma de Teología 1, q 1, art. 1," Universitas Philosophica, 35/70, (2018), pp. 131-149.

40 Suárez, D.M. Ratio et discursus totius operis..., op. cit., p. 17: «nostram philosophiam debere christianam ese».

41 Filippi, «La restitución de valor inteligible...», op. cit., p. 45: «Por eso, en lo sucesivo la metafísica no necesitará presuponer el vínculo existencial entre Dios y la creación, sino que partirá de principios propios, a priori, capaces de abarcar en sí la totalidad de lo real, incluido el mismo Ser divino. El objeto de la metafísica es el ens in quantum ens y éste, a su vez, resulta definido como conceptus entis, como un objeto puramente pensado, formal y neutro. El objeto de la metafísica, lo «real», ya no es pues, un datum, algo dado en el orden existencial, sino ante todo un cogitatum, algo pensable, reductible a términos de pura razón». 